\title{
COMPRESSION-LOADED CRACKED CYLINDER - STRESS INTENSITY FACTOR EVALUATION
}

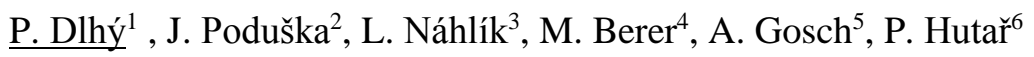

\begin{abstract}
Production of plastic parts by injection moulding is accompanied by many defects, usually caused by the shrinkage of the material. Despite the effort of manufacturers, it is not possible to get rid of all defects from manufactured parts. These defects can be places of later cracks initiation. This contribution presents developed parametrical finite element model of the central cracked polymer cylinder bearing element made by injection molding. In order to describe crack behaviour, stress intensity factor (SIF) is evaluated.
\end{abstract}

Keywords: fracture mechanics; polymer material; finite element method; contact task; rolling element

\section{Introduction}

The use of polymers is quite common in mechanical engineering nowadays. One of possible applications are polymeric bearings. Polymer materials against metals offer corrosion resistance, lower weight or less noise in service caused by higher dumping. Low cost and possibility of mass production are also valuable benefits. On the other hand, lower load capacity and sensitivity to operation temperature must be considered before application of polymers. When designing polymer parts, attention must be paid to limited fatigue capacity and lower material resistance to crack initiation as well as propagation.

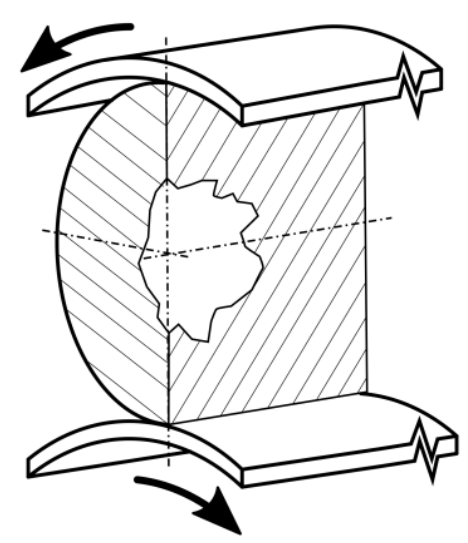

Figure 1: Polymer cylinder with central void

Polymers like polyamide (PA) types, polyoxymethylene (POM) and polyetheretherketone (PEEK) are usually used to produce polymer cylindrical bearing elements by injection moulding. Mentioned polymers are all semi-crystalline thermoplastics, which are typically showing crystallization (significant

\footnotetext{
${ }^{1}$ Pavol Dlhý; Central European Institute of Technology - Brno University of Technology and Institute of Physics of Materials, Academy of Sciences of the Czech Republic; pavol.dlhy@ ceitec.vutbr.cz

2 Jan Poduška; Brno University of Technology, Faculty of Mechanical Engineering and Institute of Physics of Materials, Academy of Sciences of Czech Republic; xpodus00@ vutbr.cz

${ }^{3}$ Luboš Náhlík; Institute of Physics of Materials, Academy of Sciences of Czech Republic; nahlik@ipm.cz

${ }^{4}$ Michael Berer; Polymer Competence Center Leoben GmbH, Roseggerstrasse 12, 8700 Leoben, Austria; michael.berer@pccl.at

${ }^{5}$ Anja Gosch; Material Science and Testing of Polymers, Montanuniversitaet Leoben, Otto Gloeckel-Straße 2, 8700 Leoben, Austria; anja.gosch@unileoben.ac.at

${ }^{6}$ Pavel Hutař; Institute of Physics of Materials, Academy of Sciences of Czech Republic; hutar@ipm.cz
} 
shrinkage because of specific arrangement of molecular chains [1]) when cooled down from the melt. This causes problems in the middle of the cylinders, where shrinkage voids appear, see Fig. 1. This problem can be reduced by better technological conditions of the moulding process (for example, the so-called holding pressure applied after filling the cavity), but it can never be fully removed.
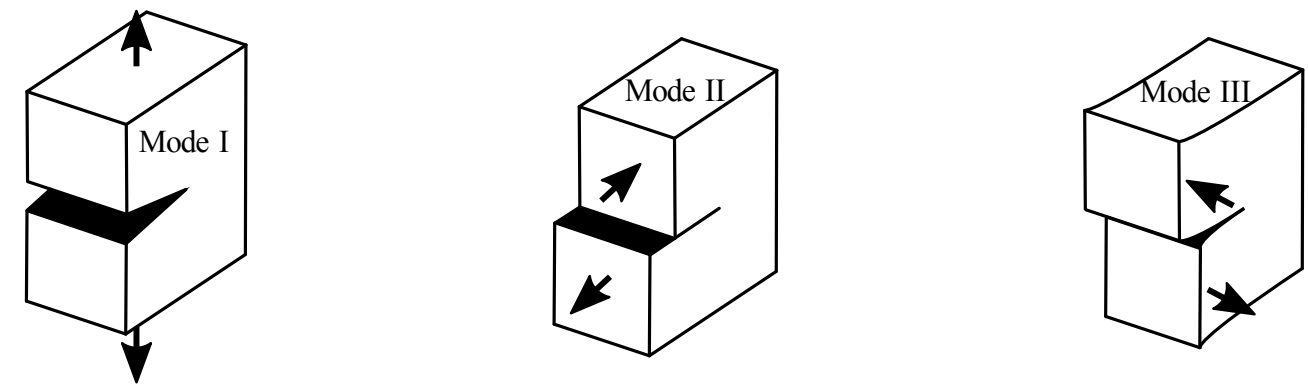

Figure 2: Stress intensity factor modes

Bearing defects are usually localized at surfaces or sub-surfaces of bearing parts [2-6]. After initiating crack from surface, crack grows towards the middle of the part until failure. In this contribution, the opposite case is presented, where crack initiates inside of the bearing element and grows towards the surface of the roller. The reason for this is that this type of parts is manufactured by injection moulding and shrinkage cavities occur in the centre of the elements. Due to non-negligible size of this shrinkage defects, fatigue crack initiates in this area. If the initial void with the starting crack is considered flat and circular while the load acts parallel to crack surface, SIF can be obtained only in mode I [7]. However, the rotation of the element must be taken into account. In the moment when the cylinder starts to rotate, modes II and III (Fig. 2) appear depending on circumferential position on the crack front and the so-called mixed mode (different combination of mode I, mode II and mode III) is obtained. Due to rotation of the element a possibility of fatigue failure should be taken into account. The stress intensity factor is a basic parameter of linear elastic fracture mechanics. SIF can be used for description of the stress field around the crack tip. The SIF is usually given a subscript to denote the mode of loading $\left(\mathrm{K}_{\mathrm{I}}, \mathrm{K}_{\mathrm{II}}, \mathrm{K}_{\mathrm{III}}\right)$ Fig. 2. Mode $\mathrm{I}$ is the opening mode and appears when external load is applied in normal way to crack plane. Mode II is defined as sliding mode or in-plane shear. Mode III refers to out of plane shear [8].

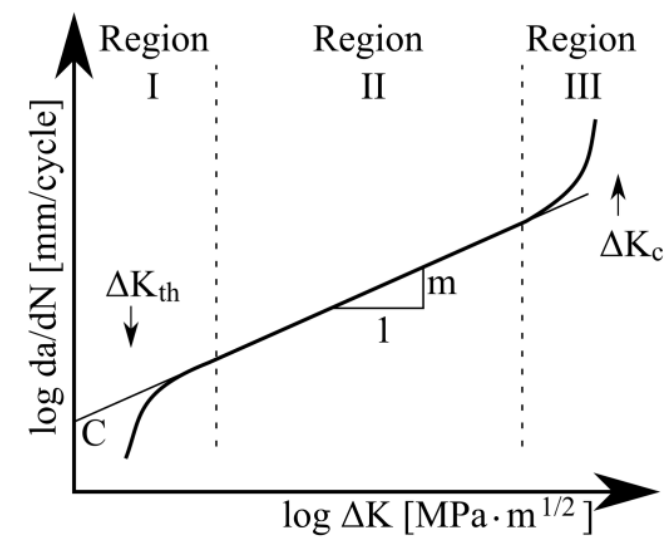

Figure 3: Plot of crack growth rate vs. stress intensity factor range

Fatigue properties are described by fatigue crack growth rate $(\mathrm{da} / \mathrm{dN})$ curve. The $\log (\mathrm{da} / \mathrm{dN})-\log$ $(\Delta \mathrm{K})$ curve (Fig. 3) usually shows a sigmoidal shape in which the mid region is associated with a stable crack propagation. From this linear region, the $\mathrm{C}$ and $\mathrm{m}$ parameters of the Paris law

$$
\frac{d a}{d N}=C \Delta K^{m}
$$

can be determined [9]. SIF range $\Delta \mathrm{K}$ is calculated from following relationship

$$
\Delta \mathrm{K}=K_{\max }-K_{\min }
$$


where $\mathrm{K}_{\max }$ is maximum value of $\mathrm{K}$ and $\mathrm{K}_{\min }$ is minimum value of $\mathrm{K}$. In order to consider mixed mode effects, it should be taken into account equivalent $\mathrm{K}$ value of all modes. However, definition of equivalent $\mathrm{K}$ is still discussed in literature [10].

Developed finite element model created in order to consider rolling effect to crack behaviour is presented in the contribution. SIF has been chosen for description of crack behaviour. As results are presented $K_{I}$ values for different crack size and for different circumferential position (Fig. 4) compared with $\mathrm{K}_{\mathrm{I}}$ values from previous study [7].

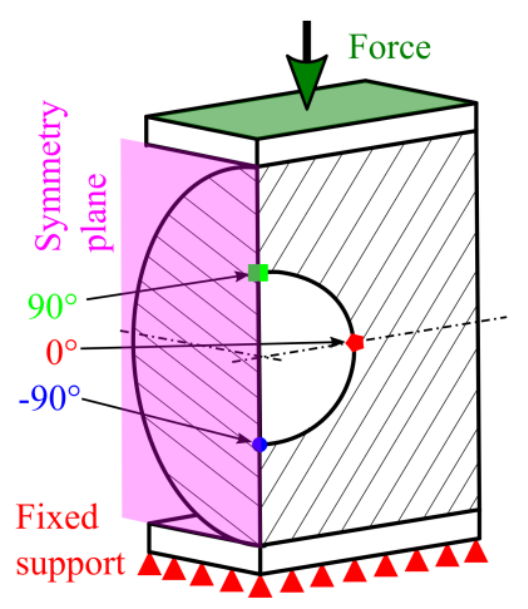

Figure 4: Illustration of considered boundary conditions of numerical model with marked circumferential position on the crack tip

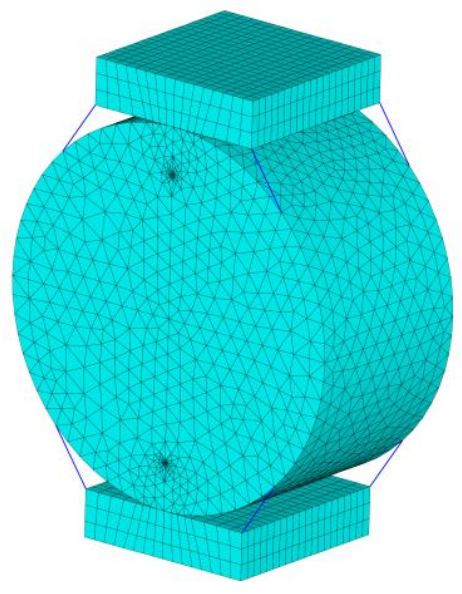

Figure 5: FEM model

\section{Numerical model}

For the whole model and numerical analysis, FEM software ANSYS was used. Length and diameter of simulated cylinder were $6 \mathrm{~mm}$. In this case, it was possible to take advantage of one symmetry plane. The finite element model had half the length (see Fig. 5), which means less elements and faster solution. Mesh around crack tip was prepared with use of crack quarter-point singular elements in crack tip vicinity (see Figs. 6 and 7) for determining $\mathrm{K}$ values. Most of the finite element mesh consisted of tetrahedrons. Regular mapped mesh was used only on the surfaces with contact elements, the crack faces and the top and bottom of the cylinders. Linear elastic isotropic material model was used for the cylinder. Material properties of polymer bearings (Young's modulus 3.6 GPa and Poisson's ratio 0.45) were considered for numerical calculations.

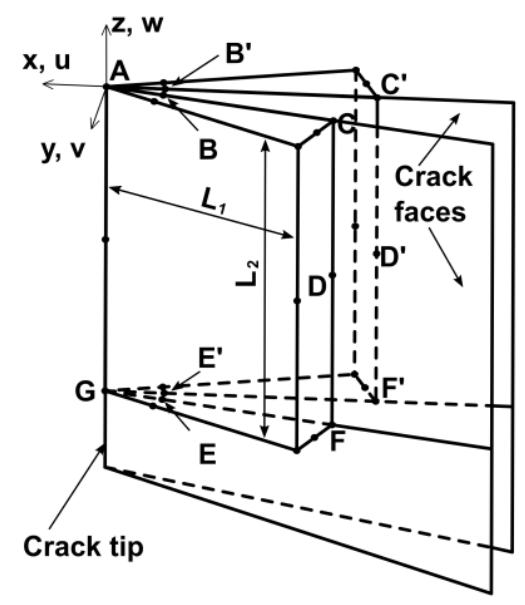

Figure 6: Crack quarter-point singular element

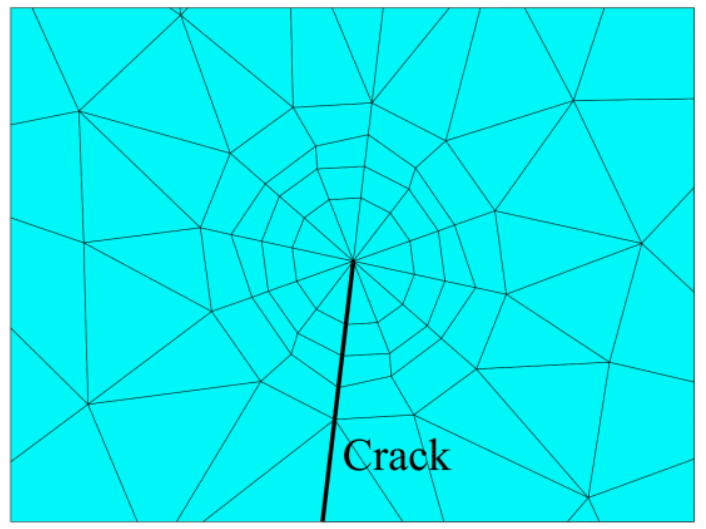

Figure 7: Detail of mesh around the crack tip

After the cylinder part, the two plates that compress the cylinder at the top and bottom were created. Mesh was created by sweeping, quadratic brick elements were used. Material model of these plates was 
also linear elastic isotropic with the Young's modulus of $210 \mathrm{GPa}$ and Poisson's ratio of 0.35 , which are common values for steel. Applied boundary conditions are shown in Fig. 4. The bottom plate was fixed and the upper plate was loaded by a compressive force of $300 \mathrm{~N}$.

To ensure better convergence, line spring elements were applied between the plates and the cylinder. Three pair-based contacts were defined. Two contacts were needed between cylinder and plates. The third contact was needed in the middle of cylinder between crack faces. Six crack lengths were considered in calculations: $0.25,0.75,1.25,1.75,2.25$ and $2.5 \mathrm{~mm}$.

The values of SIF were calculated from the displacements of the nodes of the quarter-point singular elements (which means that brick element is collapsed into quarter-point wedge and mid point nodes (points $\mathrm{B}, \mathrm{B}$ ', E and $\mathrm{E}^{\prime}$ in Fig. 6) are moved in distance $\mathrm{L}_{1} / 4$ to the crack tip) close to the crack tip using equations:

$$
\begin{gathered}
K_{I}=\frac{E}{4\left(1-v^{2}\right)} \sqrt{\frac{\pi}{2 L_{1}}}\left[2 v_{B}-v_{C}+2 v_{E}-v_{F}+v_{D}-2 v_{B^{\prime}}+v_{C^{\prime}}-2 v_{E^{\prime}}+v_{F^{\prime}}-v_{D^{\prime}}+\frac{1}{2} \eta\left(-4 v_{B}+\right.\right. \\
\left.\left.v_{C}+4 v_{E}-v_{F}+4 v_{B^{\prime}}-v_{C^{\prime}}-4 v_{E^{\prime}}+v_{F^{\prime}}\right)+\frac{1}{2} \eta^{2}\left(v_{F}+v_{C}-2 v_{D}-v_{F^{\prime}}-v_{C^{\prime}}+2 v_{D^{\prime}}\right)\right] \\
K_{I I}=\frac{E}{4\left(1-v^{2}\right)} \sqrt{\frac{\pi}{2 L_{1}}}\left[2 u_{B}-u_{C}+2 u_{E}-u_{F}+u_{D}-2 u_{B^{\prime}}+u_{C^{\prime}}-2 u_{E^{\prime}}+u_{F^{\prime}}-u_{D^{\prime}}+\frac{1}{2} \eta\left(-4 u_{B}+\right.\right. \\
\left.\left.u_{C}+4 u_{E}-u_{F}+4 u_{B^{\prime}}-u_{C^{\prime}}-4 u_{E^{\prime}}+u_{F^{\prime}}\right)+\frac{1}{2} \eta^{2}\left(u_{F}+u_{C}-2 u_{D}-u_{F^{\prime}}-u_{C^{\prime}}+2 u_{D^{\prime}}\right)\right] \\
K_{I I I}=\frac{E}{4(1+v)} \sqrt{\frac{\pi}{2 L_{1}}}\left[2 w_{B}-w_{C}+2 w_{E}-w_{F}+w_{D}-2 w_{B^{\prime}}+w_{C^{\prime}}-2 w_{E^{\prime}}+w_{F^{\prime}}-w_{D^{\prime}}+\right. \\
\frac{1}{2} \eta\left(-4 w_{B}+w_{C}+4 w_{E}-w_{F}+4 w_{B^{\prime}}-w_{C^{\prime}}-4 w_{E^{\prime}}+w_{F^{\prime}}\right)+\frac{1}{2} \eta^{2}\left(w_{F}+w_{C}-2 w_{D}-w_{F^{\prime}}-w_{C^{\prime}}+\right. \\
\left.\left.2 w_{D^{\prime}}\right)\right]
\end{gathered}
$$

where E is Young's modulus, $v$ is Poisson's ratio, $L_{1}$ and $L_{2}$ lengths defined in Fig. $6, u$ is displacement in $x$ direction for each position, $v$ is displacement in $y$ direction for each position and $w$ is displacement in $z$ direction for each position. $\eta$ is calculated from

$$
\eta=-\left(\frac{2 z}{L_{2}}+1\right)
$$

where $z$ is distance for calculated point. More details can be found in the paper [12].

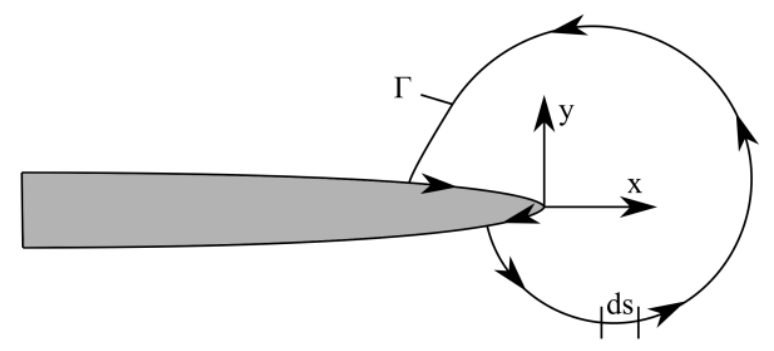

Figure 8: Path around the crack tip

In order to confirm obtained $\mathrm{K}$ values, another calculation of $\mathrm{K}$ values from J-integral by Ansys CINT command was also carried out. J-integral considers an independent path $(\Gamma)$ around the crack tip like in Fig. 8. J-integral is given by

$$
J=\int_{\Gamma}\left(w d y-T_{i} \frac{\partial u_{i}}{\partial x} d s\right),
$$

where $w$ is strain energy density, $T_{i}$ is components of the traction vector, $u_{i}$ is displacement vector components and $d s$ is length increment along the contour $\Gamma$. The strain energy density is given by

$$
w=\int_{0}^{\varepsilon_{i j}} \sigma_{i j} d \varepsilon_{i j},
$$

where $\sigma_{i j}$ is stress tensor and $\varepsilon_{i j}$ is strain tensor. 


\section{Results}

Results obtained from the model with one symmetry plane is described in the following text. Comparation of used method for evaluation of $\mathrm{K}$ values is showed in Fig. 9. Functionality of the numerical model is confirmed by comparing data with previous study, see Fig. 9 and Fig. 10.

Fig. 9 shows that values obtained from crack quarter-point singular elements and J-integral are similar and in very good agreement with former Berer's study [7]

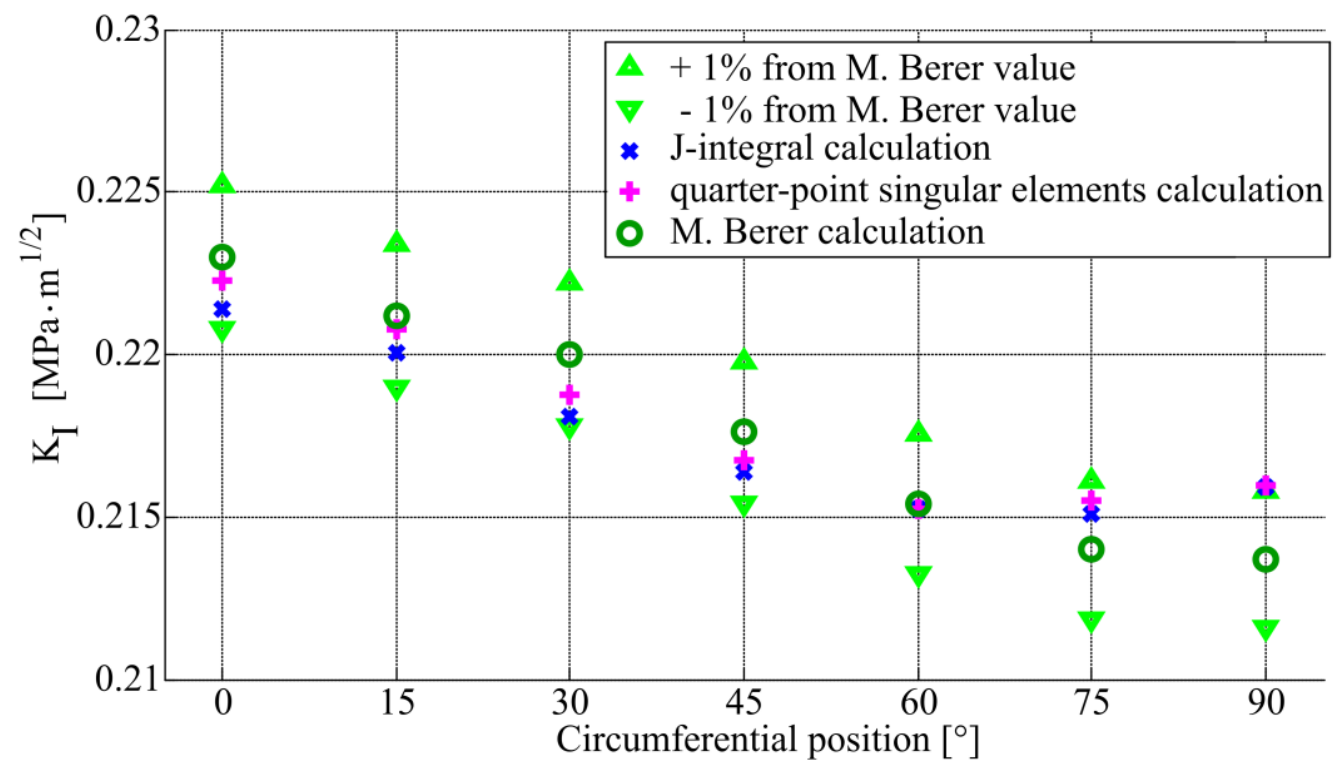

Figure 9: Difference between calculated $K_{I}$ values for crack length 1.25 mm

In Fig. 10 values of $\mathrm{K}_{\mathrm{I}}$ under different circumferential position with different crack lengths are illustrated. The difference between individual variant with the shortest crack (crack length $0.25 \mathrm{~mm}$ ) and variant with the longest crack (crack length $2.50 \mathrm{~mm}$ ) is evident. Values of $\mathrm{K}_{\mathrm{I}}$ are increasing with crack length. Increase of $K_{I}$ values for $0^{\circ}$ in comparison to $90^{\circ}$ is important especially for longer cracks.

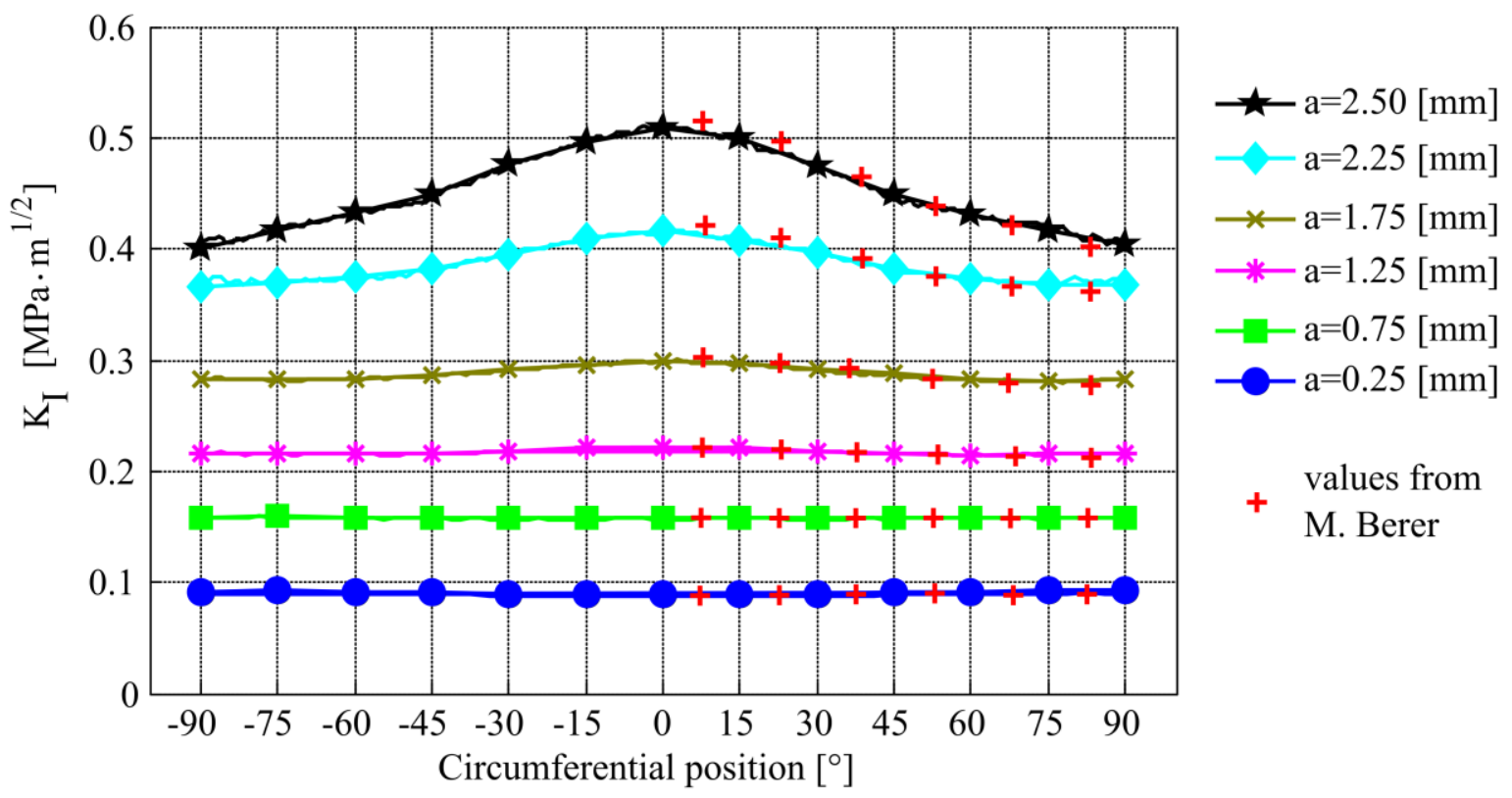

Figure 10: $K_{I}$ values in different circumferential for different crack lengths 


\section{Conclusion}

In the presented study, $\mathrm{K}_{\mathrm{I}}$ effects in compression loaded plastic cylinder with central crack was studied by using developed numerical parametrical finite element model prepared for further investigation of the crack behavior under cylinder rotation. For calculation of $\mathrm{K}_{\mathrm{I}}$ values, two different methods were used. Functionality of model was confirmed by comparison of obtained data with former study [7]. To get more precise results, a more realistic central void shape should be considered, which is the line of future work on this topic. Presented work represent first step for determination of lifetime of polymer bearings with cylindrical elements.

\section{Acknowledgement}

This research has been supported by Polymer Competence Center Leoben GmbH (PCCL, Austria) and the Ministry of Education, Youth and Sports of the Czech Republic under the project m-IPMinfra (CZ.02.1.01/0.0/0.0/16_013/0001823) and the equipment and the base of research infrastructure IPMinfra were used during the research activities.

\section{References}

[1] PAINTER, Paul C. a Michael M. COLEMAN. Fundamentals of Polymer Science: An Introductory Text. 1997. ISBN 1566765595.

[2] KADIN, Y. a A. V. RYCHAHIVSKYY. Modeling of surface cracks in rolling contact. Materials Science and Engineering A. 2012, 541(September), 143-151. ISSN 09215093.

[3] LEVESQUE, George a Nagaraj K. ARAKERE. An investigation of partial cone cracks in silicon nitride balls. International Journal of Solids and Structures. 2008, 45(25-26), 63016315. ISSN 00207683.

[4] CHEN, S. Y., T. N. FARRIS a S. CHANDRASEKARI. Contact mechanics of hertzian cone cracking. International Journal of Solids and Structures. 1995, 32(3-4). ISSN 00207683.

[5] FERNANDES, P. J.L. Contact fatigue in rolling-element bearings. Engineering Failure Analysis. 1997, 4(2), 155-160. ISSN 13506307.

[6] UPADHYAY, R. K., L. A. KUMARASWAMIDHAS a Md Sikandar AZAM. Rolling element bearing failure analysis: A case study. Case Studies in Engineering Failure Analysis. 2013, 1(1), 15-17. ISSN 22132902.

[7] BERER, M., I. MITEV a G. PINTER. Finite element study of mode I crack opening effects in compression-loaded cracked cylinders. Engineering Fracture Mechanics. 2017, 175, 1-14. ISSN 00137944.

[8] ANDERSON, T. L. Fracture mechanics : fundamentals and applications. Third. B.m.: Taylor \& Francis Group, 2005. ISBN 9781420058215.

[9] LÜSTL, Sigrid, P. M. VISAKH a Sarath CHANDRAN. Polyoxymethylene Handbook: Structure, Properties, Applications and Their Nanocomposites. Hoboken, NJ, USA: John Wiley \& Sons, Inc., 2014. ISBN 9781118914458.

[10] MUNZ, Dietrich a Theo FETT. Ceramics. Berlin, Heidelberg: Springer Berlin Heidelberg, 1999. Springer Series in Materials Science. ISBN 978-3-642-58407-7.

[11] ROYCHOWDHURY, S. AND DODDS, R.H. Three-dimensional effects on fatigue crack closure in the small-scale yielding regime - a finite element study. Materials and Structures. 2003, 2003(January), 663-673. ISSN 8756758X.

[12] INGRAFFEA, Anthony R. a Corneliu MANU. Stress-intensity factor computation in three dimensions with quarter-point elements. International Journal for Numerical Methods in Engineering. 1980, 15(10), 1427-1445. ISSN 10970207. 